\title{
PREVALENCE OF NASAL CARRIAGE OF METHICILLIN-RESISTANT STAPHYLOCOCCUS AUREUS AMONG HEALTHCARE WORKERS IN THE DEPARTMENTS OF OTORINOLARYNGOLOGY AND DENTISTRY IN KYIV, UKRAINE
}

10.36740/WLek202012101

\author{
Aidyn G. Salmanov', Taras P. Bondar², Yaroslav V. Shkorbotun', Evelina A. Chumak², Volodymyr O. Shkorbotun', \\ Olena V. Dementieva ${ }^{2}$, Vadim V. Pererva ${ }^{2}$ \\ 'SHUPYK NATIONAL MEDICAL ACADEMY OF POSTGRADUATE EDUCATION, KYIV, UKRAINE \\ ${ }^{2}$ BOGOMOLETS NATIONAL MEDICAL UNIVERSITY, KYIV, UKRAINE \\ ${ }^{3}$ RESEARCH AND PRACTICAL CENTER OF PREVENTIVE AND CLINICAL MEDICINE OF STATE ADMINISTRATIVE DEPARTMENT, KYIV, UKRAINE
}

\begin{abstract}
The aim: To obtain the first estimates of the current prevalence of nasal carriage of methicillin-resistant Staphylococcus aureus (MRSA) among healthcare workers (HCWs) in the departments of Otorinolaryngology and Dentistry and to determine of genes virulence factors (Panton Valentine Leukocidine (PVL) genes).

Materials and methods: We performed a multicenter cross-sectional study. The susceptibility to antibiotics was determined by disk diffusion method according to the European Committee on Antimicrobial Susceptibility Testing. The virulence factor encoding genes, mecA, lukS-lukF, were detected by Polymerase Chain Reaction (PCR).

Results: Incidence rate of S. aureus nasal carriage among $\mathrm{HCW}$ s was $36.2 \%$, whereas MRSA carriage was $17 \%$. Prevalence of MRSA carriage rate was $34.9 \%$ in 0 torhinolaryngology departments and $9.7 \%$ in Dentistry. PCR testing confirmed that all MRSA strains were mecA gene-positive. The virulence factor encoding genes were detected in $82.3 \%$ of the S. aureus isolates from HCWs. Among S.aureus, the lukS-lukF genes were detected in over 59\% of the strains. The lukS-lukFgenes were detected in $55.5 \%$ of MRSA and in $58.9 \%$ of MSSA strains. LukS-IukF genes were most commonly co-present in MRSA strains. No significant difference was detected between the occurrences of $/ u k S-l u k F g e n e s(P>0.05)$. Conclusions: Personnell in otorhinolaryngology and dentistry departments have a high rate of nasal colonization of MRSA. This carrier state may be an important risk factor for transmission MRSA from physicians and nurses to patients and vice-versa. Screening for MRSA nasal carriage of HCWs is a key element in enabling infection control measures and early therapeutic decisions.
\end{abstract}

KEY WORDS: Staphylococcus aureus, nasal carriage, MRSA, healthcare workers, Otorinolaryngology, Dentistry, Panton Valentine Leukocidine

Wiad Lek. 2020;73(12 p. I):2563-2567

\section{INTRODUCTION}

Staphylococcus aureus is a very common bacterium that is both a normal flora and main human pathogen of healthcare-associated, and community acquired infections resulting to widespread morbidity and mortality. [1-5]. In Europe, the proportion of methicillin resistance in strains of S. aureus isolates in infected patients varied in 2011 from less than $0.5 \%$ to more than $50 \%$ [6]. In the United States, the proportion of methicillin resistance in $S$. aureus strains approached almost $60 \%$ in 2003 , with an average rate of resistance over the period 1998-2002 of around 50\% [7].

Approximately $30 \%$ of the world human population is carriers of S. aureus [8]. The prevalence of $S$. aureus nasal carriage in Ukraine was $40.4 \%$. We found that $9.1 \%$ of the strains were classified as methicillin resistance $S$. aureus (MRSA) [9]. A recent review estimated prevalence of MRSA in healthcare workers (HCWs) to be $4.6 \%$. However, MRSA carriage in HCWs in non-outbreak settings is thought to be higher than in an outbreak situation, due to increased hygiene awareness in outbreaks, but valid data are missing [10].
In Ukraine nasal carriage of MRSA in HCWs was $16.6 \%$. The frequency of MRSA carriage also varied according to the department/ward. The highest prevalence of nasal carriage of MRSA was in the surgical wards [11]. However, the burden of MRSA colonisation seems to extend beyond the hospitals to Dentistry setting and outpatient Otorinolaryngology care.

The pathogenicity of $S$. aureus results from its ability to produce specific toxins and hydrolytic enzymes. However, the studies regarding the prevalence of MRSA strains and distribution of genes encoding virulence factors, which have colonized pathients and HCW s in Ukraine, is limited.

\section{THE AIM}

The aim of this study was to obtain the first estimates of the current prevalence of nasal carriage of MRSA among healthcare workers in the departments of Otorinolaryngology and Dentistry and to determine of genes virulence factors. 


\section{MATERIALS AND METHODS}

\section{STUDY DESIGN AND SETTING}

This cross-sectional multicenter study was conducted between January 2020 and June 2020. The study population consisted of healthcare workers in the 7 Dentistry setting and 8 outpatient Otorinolaryngology departments in Kyiv, Ukraine. We have included Dentistry setting and Otorinolaryngology departments that are similar in terms of medical equipment, personnel, and laboratory facilities.

\section{DATA COLLECTION}

Nasal swabs were taken from 218 randomly selected HCWs (doctors, nurses and other workers). Only one isolate from each HCWs was included in the study. HCWs with a history of upper respiratory tract infection, fever, and recent nasal surgery, use of nasal medications or antimicrobial therapy were excluded. HCWs with a history of upper respiratory tract infection, fever, and recent nasal surgery, use of nasal medications or antimicrobial therapy were excluded. All personnel included in the study were full-time workers Dentistry setting and outpatient Otorinolaryngology departments. Personnel who worked part time were excluded from the study.

\section{MICROBIOLOGICAL METHODS}

Nasal swabs were collected from the anterior nares of the HCWs using a cotton swab in AMIES transport medium. The swabs were immediately transported to the microbiology laboratory for further processing. Microbial isolates were identified using standard microbiological techniques, including automated microbiology testing (Vitek-2; bioMe'rieux, Marcy l'Etoile, France).

The susceptibility pattern for several classes of antibiotics was determined by disk diffusion method according to the European Committee on Antimicrobial Susceptibility Testing (EUCAST) guidelines. The tested antimicrobial agents were: cefoxitin, gentamicin, tetracycline, trimethoprim-sulfamethoxazole, erythromycin, clindamycin, ciprofloxacin, mupirocin, rifampicin, fusidic acid and penicillin. Isolates were classified as susceptible or resistant based on S. aureus epidemiological cut-off values issued by the EUCAST. Erythromycin-induced clindamycin resistance was detected by Disk approximation test (D-test).

\section{POLYMERASE CHAIN REACTION (PCR)}

DNA was extracted using the Genomic DNA Extraction kit (EURx, Gdansk, Poland) according to the manufacturer's guidelines. The cefoxitin-resistant isolates were analyzed for the presence of the mecA gene and $f e m A$ endogenous control gene using PCR, as previously described. The primers used to amplify the mecA gene were (forward: 5'- AAGCGACTTCATCTATTAGGTTAT-3' and reverse: 5'-TATATTCTTCGTTACTCATGCCATAC-3'; [12]. The primers used to amplify the $f e m A$ gene were forward:
5'-AACTGTTGGCCACTATGAGT-3' and reverse: 5'-CCAGCATTACCTGTAATCTCG-3'; [13].

Positive and negative controls were added in each run, we used reference strains that are $m e c A$ positive and negative. PCR, used to detect PVL (lukS and lukF genes), was performed as previously described [14]. The primers used to amplify the lukS-PV gene were 5'AGTGAACTTATCTTTCTATTGAAAAACACTC - 3 ' and $l u k F$ gene were 5'- GCATCAASTGTATTGGATAGCAAAAGC -3' [14].

\section{ETHICS}

The study was approved by the Ethics Committee of Shupyk National Medical Academy of Postgraduate Education (Kyiv, Ukraine). All study staff prior to specimen collection voluntarily agreed to participate in the study and signed an informed consent form. All study personnel data were anonymised prior to the analysis. Ethical considerations including privacy of personal data were considered during all steps of the research.

\section{STATISTICAL ANALYSIS}

The analysis of statistical data was performed using Excel (Microsoft Corp., Redmond, WA, USA). Results are expressed as median (range), mean standard deviation for continuous variables, and number and corresponding percentage for qualitative variables. Comparisons were undertaken using Student's t-test and Fisher's exact test for categorical variables. Statistical significance was defined as $P<0.05$.

\section{RESULTS}

\section{PREVALENCE OF MRSA CARRIAGE}

The during study period a total $218 \mathrm{HCW}$ s were screened for S.aureus carriage. The mean age of participants was $32.41 \pm 8.29$ years (range $19-74$ years) with a male-tofemale ratio of 0.47 . Overall, 79 bacterial isolates were phenotypically identified as $S$. aureus. All of the 79 isolates were confirmed as $S$. aureus by targeting the $f e m A$ gene.

Accordingly, the rate of nasal carriage of $S$. aureus among HCWs is $36.2 \%$ (79/218). Among them 49 (62\%) were identified as MRSA using the oxacillin disc resistance. However, using PCR targeting the mecA gene in S. aureus, only $37(46.8 \%)$ isolates were confirmed as MRSA. The prevalence of S.aureus and MRSA carriage among the different HCWs is shown in Table I.

The overall nasal carriage rate of MRSA was 17\% (37/218). The prevalence of nasal carriage rate of MRSA was 34.9\% in Otorinolaryngology departments and 9.7\% in Dentistry setting. S.aureus carriage rate was highest in Otorinolaryngology departments among doctors 62.5\% $(15 / 24)$, whereas carriage among nurses was $42.9 \%(9 / 21)$ and cleaners $38.9 \%(7 / 18)$.

MRSA carriage rate was significantly highest $(\mathrm{P}=0.001)$ among doctors $41.7 \%(10 / 24)$ compared to other professions. $33.3 \%(7 / 21)$ of the isolates of S. aureus carried by the 
Table I. Prevalence of S.aureus and MRSA carriage among the different HCWs in Kyiv, Ukraine

\begin{tabular}{ccccc}
\hline HCWs & $\begin{array}{c}\text { Number } \\
\text { of samples }\end{array}$ & $\begin{array}{c}\text { Number of S.aureus } \\
\text { carriers (n/\%) }\end{array}$ & $\begin{array}{c}\text { Number of MRSA } \\
\text { carriers (n/\%) }\end{array}$ & P-value \\
\hline Otorinolaryngology & 63 & $31(49.2 \%)$ & $13(34.9 \%)$ & 0.051 \\
\hline Doctor & 24 & $9(62.5 \%)$ & $7(33.3 \%)$ \\
\hline Nurses & 21 & $9(42.9 \%)$ & $5(27.8 \%)$ \\
\hline Cleaners & 18 & $7(38.9 \%)$ & $15(9.7 \%)$ \\
\hline Dentistry & 155 & $48(31 \%)$ & $10(20 \%)$ \\
\hline Doctor & 50 & $21(42 \%)$ & $3(4.8 \%)$ \\
\hline Nurses & 62 & $18(29 \%)$ & $2(4.7 \%)$ \\
\hline Cleaners & 43 & $9(20.9 \%)$ & $37(17 \%)$ \\
\hline Total & 218 & $79(36.2 \%)$ & \\
\hline
\end{tabular}

HCWs - healthcare workers

MRSA - methicillin resistant $S$. aureus

Table II. Distribution of S.aureus and MRSA carriage among HCWs in the different Dentistry departments.

\begin{tabular}{|c|c|c|c|}
\hline Department & $\begin{array}{l}\text { Number } \\
\text { of samples } \\
\text { (n) }\end{array}$ & $\begin{array}{l}\text { Number of S.aureus } \\
\text { carriage } \\
\text { (n/\%) }\end{array}$ & $\begin{array}{c}\text { Number of } \\
\text { MRSA carriers } \\
\text { (n/\%) }\end{array}$ \\
\hline Dental Surgery & 34 & $18(52.9 \%)$ & $8(23.5 \%)$ \\
\hline Dental Therapeutic & 71 & $20(28.2 \%)$ & $5(7 \%)$ \\
\hline Dental Orthopeadic & 38 & $9(23.7 \%)$ & $2(5.3 \%)$ \\
\hline Dental Radiodiagnostics & 12 & $1(8.3 \%)$ & 0 \\
\hline Total & 155 & $48(31 \%)$ & $15(9.7 \%)$ \\
\hline
\end{tabular}

HCWs - healthcare workers

MRSA - methicillin-resistant Staphylococcus aureus

nurses were MRSA. The carriage rate among cleaners was $27.8 \%$ (5/18). In Dentistry setting $S$. aureus carriage rate was highest among doctors $42 \%(21 / 50)$, whereas carriage among nurses was 29\% (18/62) and cleaners 20.9\% (9/43). MRSA carriage rate was significantly highest $(\mathrm{P}=0.001)$ among doctors 20\% (10/50) compared to other HCWs. $4.8 \%(3 / 62)$ of the isolates of $S$. aureus carried by the nurses were MRSA. The carriage rate among cleaners was $4.7 \%$ (2/43) (Table I).

The frequency of $S$. aureus carriage also varied according to the Dentsrty departments. The highest rate of S. aureus carriage was found in HCWs of the surgical departments (52.9\%), followed by dental therapeutic and dental orthopeadic departments (28.2 and $23.7 \%$ respectively). On the other hand, the highest MRSA carriage rate was found in surgery wards (23.5\%). Carriage of MRSA in other Dentsrty departments was not high (Table II).

\section{ANTIBIOTIC SUSCEPTIBILITY}

All $S$. aureus strains isolated from HCWs were susceptible to fusidic acid. $11.4 \%$ (9/79) of the strains S.aureus were classified as resistance to mupirocin. The ability to produce beta-lactamases was detected in 69.6\% (55/79) of the strains. MSSA and MRSA strains displayed no statistical difference in beta-lactamase secretion $(P>0.05)$. $72.1 \%$ of MSSA iso- lates were resistant to penicillin. Resistance to erythromycin was observed in $65.9 \%$, to tetracycline in $14.5 \%$, to gentamicin in $12.6 \%$, to clindamycin in $16.5 \%$, rifampicin in $18.3 \%$ and to trimethoprim-sulfamethoxazole in $11.4 \%$ of MSSA isolates. All MRSA strains were fusidic acid-susceptible. Seven out of 37 (18.9\%) MRSA strains were trimethoprim/ sulfamethoxazole-susceptible. 24 out of 37 (64.9\%) MRSA were susceptible to mupirocin and gentamicin. $77.8 \%$ of those strains presented resistance to tetracycline, erythromycin, and clindamycin. Erythromycin-induced clindamycin resistance occurred in 31.4\% MRSA strains and in 5.6\% MSSA strains. The erythromycin-induced clindamycin resistance rate was significantly higher among MRSA strains, if compared with MSSA strains $(\mathrm{P}<0.05)$.

\section{DISTRIBUTION OF VIRULENCE FACTOR ENCODING GENES}

The virulence factor encoding genes were detected in $82.3 \%$ $(65 / 79)$ of the S. aureus isolates from HCWs. Among the 79 strains S.aureus, the lukS-lukF genes were detected in over $59 \%$ of the strains. The $l u k S-l u k F$ genes were detected in $55.5 \%$ of MRSA and in 58.9\% of MSSA strains. LukS-lukF genes were most commonly co-present in MRSA strains. No significant difference was detected between the occurrences of lukS-lukF genes $(\mathrm{P}>0.05)$. 


\section{DISCUSSION}

There is a paucity of information on the role of human carriage among HCWs, personnel that could easily carry and spread $S$. aureus strains to patients. There is no evidence of $S$. aureus susceptibility and occurrence of virulence encoding genes within the Ukrainian HCWs. This is the first study were to obtain of the current prevalence of nasal carriage of MRSA among healthcare workers in the departments of Otorinolaryngology and Dentistry and to determine of genes virulence factors. The present study reports that the prevalence of $S$. aureus nasal carriage among HCWs in Kyiv, Ukraine was 36.2\%, whereas MRSA carriage was $17 \%$. Prevalence of nasal carriage of S.aureus among healthcare workers in the departments of Otorinolaryngology and Dentistry were $49.2 \%$ and $31 \%$ respectively. The MRSA carriage rate was $34.9 \%$ in otorhinolaryngology departments and $9.7 \%$ in dentistry. MRSA carriage rate was significantly highest among doctors in surgical departments.

An overview of the published work highlights that carriage of MSSA or MRSA in HCWs occurs at a variable rate in countries with very different public health and social structures, however, there is no simple way to predict carriage rates on the basis of the mentioned variables. Also, differences in the prevalence of nasal carriage of $S$. aureus strains may be due in part to differences in the quality and size of samples and the use of different techniques and different interpretation guidelines. Data of our study are comparable to others reported in the literature [15-18].

Despite the possible role that HCWs may perform in dissemination of MSSA and MRSA strains, relatively few reports have addressed this issue. In our study, neither MSSA nor MRSA fusidic acid resistant strains were observed using the disk diffusion method. These data differ from the data concerning other countries $[19,20]$. The absence of fusidic acid resistant strains can be explained by their limited use in Ukraine. Susceptibility to the other antimicrobials was also on a high level (tetracycline, gentamicin, clindamycin, rifampicin, clindamycin and trimethoprim/ sulphamethoxazole). In our study MRSA came up to $17 \%$. Thus, this is a major problem in the treatment of $S$. aureus infections. PCR testing confirmed that all MRSA strains isolated from our HCWs were mecA gene-positive.

In the present study, we found a high prevalence of PVL encoding genes. The virulence factor encoding genes were detected in $82.3 \%$ of the S. aureus isolates from HCWs. Over $59 \%$ strains isolated from nares in individuals with no staphylococcal infection symptoms, were luk-PV-positive (lukS-lukF genes). This evidence contrasts with previous reports. For instance, the prevalence of PVL-positive $S$. aureus nasal colonization in Dutch general practice patients was $0.6 \%$ [19]. Furthermore, a PVL prevalence of $38.9 \%$ was observed in S. aureus and it caused abscesses, arthritis, and soft-tissue infections [19]. The prevalence of PVL-positive S. aureus in nasal colonization was $2.4 \%$ in the United States [21]. According was estimated that PVL-positive S. aureus was more prevalent pathogen in the tropics and subtropics, if compared with European coun- tries [22]. Travellers to tropical and subtropical countries are exposed to a higher risk of skin and soft-tissue infections. This phenomenon results from a higher PVL-positive $S$. aureus occurrence in tropical and subtropical countries [23]. Similarly, job seekers travelling from Ukraine could be a source of toxin-producing strains.

\section{LIMITATIONS}

The current study had several limitations. Most importantly, the small size limited the broad representative significance of the research. Second, sampling of only the nostrils without including other body parts may underestimate the frequency of MRSA colonization. Despite the above limitations, our results confirmed the nasal S. aureus colonization in a special population, Otorinolaryngology and Dentistry staff in local region.

A limitation of our study is that we studied isolates deriving only from Kyiv region of Ukraine and it cannot be representative of the overall Ukrainian situation. Furthermore, we did not perform spa typing and therefore we could not discriminate among different strains of $S$. aureus. Further studies are required to address those limitations. A systematic surveillance system can help prevent transmission and spread of drug resistant toxin producing $S$. aureus strains.

\section{CONCLUSIONS}

Health care workers in otorhinolaryngology and dentistry departments have a high rate of nasal colonization of MRSA. All MRSA isolates tested positive for the mecA gene. We also found a high prevalence of PVL- encoding genes among $S$. aureus nasal carriage strains. This carrier state may also be an important risk factor for transmission MRSA from physicians and nurses to patients and vice-versa. Screening for MRSA nasal carriage of HCWs in otorhinolaryngology and dentistry departments is a key element in enabling infection control measures and early therapeutic decisions. It is of importance to follow the evolution of resistance to antibiotics in this species, especially to $\beta$-lactams. A systematic surveillance system can help prevent transmission and spread of drug resistant toxin producing $S$. aureus strains.

\section{REFERENCES}

1. Price J.R., Cole K., Bexley A. et al. Transmission of Staphylococcus aureus between health-care workers, the environment, and patients in an intensive care unit: a longitudinal cohort study based on whole-genome sequencing. Lancet Infect Dis. 2017;17(2):207-214. doi:10.1016/S14733099(16)30413-3.

2. Salmanov A.G., Vdovychenko S.Y., Litus 0.I. et al. Prevalence of healthcare-associated infections and antimicrobial resistance of the responsible pathogens in Ukraine: Results of a multicenter study (2014-2016). Am J Infect Control. 2019;47(6):e15-e20. doi: 10.1016/j. ajic.2019.03.007.

3. Salmanov A.G., Shkorbotun V.0., Shkorbotun Y.V. Antimicrobial resistance of Staphylococcus aureus causing of surgical site infections in ear, nose and throat surgery. Wiad Lek. 2019;72(2):154-158. 
4. Salmanov A., Vozianov S., Kryzhevsky V. et al. Prevalence of healthcareassociated infections and antimicrobial resistance in acute care hospitals in Kyiv, Ukraine. J Hosp Infect. 2019;102(4):431-437. doi: 10.1016/j. jhin.2019.03.008.

5. Salmanov A.G., Voronenko Yu.V., Vozianov S.O. et al.Bloodstream infections and antimicrobial resistance of responsible pathogens in Ukraine: results of a multicenter study (2013-2015). Wiad Lek. 2019;72 (11/1):1069-2075. doi: 10.36740/WLek201911101.

6. European Centre for Disease Prevention and Control. Antimicrobial resistance surveillance in Europe 2015. Annual Report of the European Antimicrobial Resistance Surveillance Network (EARS-Net). Stockholm: ECDC. 2017.

7. NNIS. National Nosocomial Infections Surveillance (NNIS) System Report, data summary from January 1992 through June 2004, issued October 2004. Am J Infect Control. 2004;14:470-485.

8. Mulcahy M.E., McLoughlin R.M. Host-Bacterial Crosstalk Determines Staphylococcus aureus Nasal Colonization. Trends Microbiol. 2016;24(11):872-886. doi: 10.1016/j.tim.2016.06.012.

9. Netsvyetayeva I., Fraczek M., Piskorska K. et al. Staphylococcus aureus nasal carriage in Ukraine: antibacterial resistance and virulence factor encoding genes. BMC Infect Dis. 2014;14:128. doi: 10.1186/1471-233414-128.

10. Dulon M., Peters C., Schablon A. et al. MRSA carriage among healthcare workers in non-outbreak settings in Europe and the United States: a systematic review. BMC Infect Dis. 2014;14:363. doi: 10.1186/14712334-14-363.

11. Salmanov A.G., Verner O.M., Shelkova N.G. et al. Prevalence of Nasal Carriage of Staphylococcus aureus and its Antibiotic Susceptibility among HealthcareWorkers (HCWs) in Ukraine. International Journal of Antibiotics and Probiotics. 2018;2(1):30-41. doi: 10.31405/ijap.2-1.18.03.

12. Paule S.M., Pasquariello A.C., Thomson R.B. et al. Real-time PCR can rapidly detect methicillin-susceptible and methicillin-resistant Staphylococcus aureus directly from positive blood culture bottles. Am J Clin Pathol. 2005;124:404-407. doi: 10.1309/6EA3U9V8NCLLGKQN.

13. Paule S.M., Pasquariello A.C., Hacek D.M. et al. Direct detection of Staphylococcus aureus from adult and neonate nasal swab specimens using real-time polymerase chain reaction. J Mol Diagn. 2004;6:191196. doi: 10.1016/S1525-1578(10)60509-0

14. Jarraud S., Mougel C., Thioulouse J. et al. Relationships between Staphylococcus aureus genetic background, virulence factors, agr groups (alleles), and human disease. Infect Immun. 2002;70(2):631-641. doi:10.1128/iai.70.2.631-641.2002

15. Castro A., Komora N., Ferreira V. et al. Prevalence of Staphylococcus aureus from nares and hands on health care professionals in a Portuguese Hospital. J Appl Microbiol. 2016;121(3):831-839. doi:10.1111/jam. 13186

16. Dulon M., Peters C., Schablon A. et al. MRSA carriage among healthcare workers in non-outbreak settings in Europe and the United States: a systematic review. BMC Infect Dis. 2014;14:363. doi: 10.1186/14712334-14-363.

17. Emaneini M., Jabalameli F., Rahdar H. et al. Nasal carriage rate of methicillin resistant Staphylococcus aureus among Iranian healthcare workers: a systematic review and meta-analysis. Rev Soc Bras Med Trop. 2017; 50(5):590-597. doi: 10.1590/0037-8682-0534-2016.

18. Boncompain C.A., Suárez C.A., Morbidoni H.R. Staphylococcus aureus nasal carriage in health care workers: First report from a major public hospital in Argentina. Rev Argent Microbiol. 2017;49(2):125-131. doi: 10.1016/j.ram.2016.12.007.
19. Donker G.A., Deurenberg R.H., Driessen C. et al. The population structure of Staphylococcus aureus among general practice patients from The Netherlands. Clin Microbiol Infect. 2009;15(2):137-143. doi:10.1111/j.1469-0691.2008.02662.x

20. MunckhofW.J., .Nimmo G.R., Schooneveldt J.M. et al. Nasal carriage of Staphylococcus aureus, including community-associated methicillinresistant strains, in Queensland adults. Clinical microbiology and infection : the official publication of the European Society of Clinical Microbiology and Infectious Diseases, 2009;15(2), 149-155. doi: 10.1111/j.1469-0691.2008.02652.x

21. Kuehnert M.J., Kruszon-Moran D., Hill H.A. et al. Prevalence of Staphylococcus aureus nasal colonization in the United States, 2001-2002. J Infect Dis. 2006;14(2):172-179. doi: 10.1086/499632.

22. Zanger P., Nurjadi D., Schleucher R. et al. Import and spread of PantonValentine Leukocidin-positive Staphylococcus aureus through nasal carriage and skin infections in travelers returning from the tropics and subtropics. Clin Infect Dis. 2012;54(4):483-92. doi: 10.1093/cid/cir822.

23. Breurec S., Fall C., Pouillot R. et al. Epidemiology of methicillinsusceptible Staphylococcus aureus lineages in five major African towns: high prevalence of Panton-Valentine leukocidin genes. Clin Microbiol Infect. 2011;17(4):633-9. doi: 10.1111/j.1469-0691.2010.03320.x.

We would like to thank all workers Institute of Molecular Biology and Genetics of Ukraine who contributed to determine of genes virulence factors S.aureus. This work was supported by the Ministry of Health of Ukraine.

\section{ORCID and contributorship:}

Aidyn G. Salmanov: 0000-0002-4673-1154 ${ }^{\text {A,C,D,E,F }}$

Taras P. Bondar: 0000-0003-0537-8021 B,C,D,F

Yaroslav V. Shkorbotun: 0000-0002-3103-7194 ${ }^{B, C, D, F}$

Evelina A. Chumak: $0000000329675346^{\text {B,C,D,F }}$

Volodymyr O. Shkorbotun: 0000-0003-0769-6242 ${ }^{\text {B,C,F }}$

Olena V. Dementieva: $000000027049518 X^{B, C, F}$

Vadim V. Pererva: 0000-0002-7619-2016 ${ }^{B, C, F}$

\section{Conflict of interest:}

The Authors declare no conflict of interest

\section{CORRESPONDING AUTHOR \\ Aidyn G. Salmanov}

Shupyk National Medical Academy of Postgraduate Education

9 Dorohozhytska St., 04112, Kyiv, Ukraine

tel: +380667997631

e-mail:mozsago@gmail.com

Received: 09.08.2020

Accepted: 20.11 .2020

A - Work concept and design, B - Data collection and analysis, C - Responsibility for statistical analysis, D-Writing the article, $\mathbf{E}$-Critical review, $\mathbf{F}-$ Final approval of the article 